(C) 2021, The Authors. Published by Elsevier Inc. and Fass Inc. on behalf of the American Dairy Science Association ${ }^{\circledR}$. This is an open access article under the CC BY-NC-ND license (http://creativecommons.org/licenses/by-nc-nd/4.0/).

\title{
Alterations in immune and antioxidant gene networks by gamma-D- glutamyl-meso-diaminopimelic acid in bovine mammary epithelial cells are attenuated by in vitro supply of methionine and arginine
}

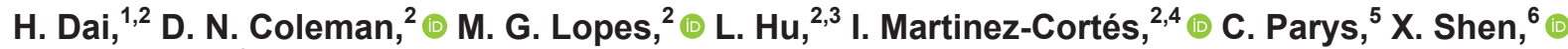 \\ and J. J. Loor ${ }^{2 *}$ (D) \\ ${ }^{1}$ College of Veterinary Medicine, Henan Agricultural University, Zhengzhou 450046, P. R. China \\ ${ }^{2}$ Department of Animal Sciences and Division of Nutritional Sciences, University of Illinois, Urbana 61801 \\ ${ }^{3}$ College of Animal Science and Technology, Yangzhou University, Yangzhou 225009, P. R. China \\ ${ }^{4}$ Agricultural and Animal Production Department, UAM-Xochimilco, Mexico City, Mexico 04960 \\ ${ }^{5}$ Evonik Nutrition \& Care GmbH, Hanau-Wolfgang, 63457, Germany \\ ${ }^{6}$ College of Veterinary Medicine, Nanjing Agricultural University, Nanjing 210095, P. R. China
}

\begin{abstract}
Nucleotide-binding oligomerization domain (NOD)like receptor 1 (NOD1) is a cytosolic pattern recognition receptor with a crucial role in the innate immune response of cells triggered by the presence of compounds such as gamma-D-glutamyl-meso-diaminopimelic acid (iE-DAP) present in the peptidoglycan of all gramnegative and certain gram-positive bacteria. Methionine (Met) and arginine (Arg) are functional AA with immunomodulatory properties. In the present study, we aimed to assess the effect of increased Met and Arg supply on mRNA abundance of genes associated with innate immune response, antioxidant function, and AA metabolism during iE-DAP challenge in bovine mammary epithelial cells (BMEC). Primary BMEC ( $\mathrm{n}=4$ per treatment) were precultured in modified medium for $12 \mathrm{~h}$ with the following AA formulations: ideal profile of AA (control), increased Met supply (incMet), increased Arg supply (incArg), or increased supply of Met plus Arg (incMetArg). Subsequently, cells were challenged with or without iE-DAP $(10 \mu \mathrm{g} / \mathrm{mL})$ for 6 h. Data were analyzed as a $2 \times 2 \times 2$ factorial using the MIXED procedure of SAS 9.4. Greater mRNA abundance of NOD1, the antioxidant enzyme SOD1, and AA transporters (SLC7A1 and SLC3A2) was observed in the incMet cells after iE-DAP stimulation. Although increased Met alone had no effect, incMetArg led to greater abundance of the inflammatory cytokine IL-6, and the antioxidant enzyme GPX1 after iE-DAP stimulation. The increased Arg alone downregulated NOD1 after iE-DAP stimulation, coupled with a downregulation in the AA transporters mRNA abundance
\end{abstract}

Received July 16, 2020.

Accepted September 8, 2020.

*Corresponding author: jloor@illinois.edu
(SLC7A1, SLC7A5, SLC3A2, and SLC38A9), and upregulation in GSS and KEAP1 mRNA abundance. Overall, the data indicated that increased supply of both Met and Arg in the culture medium were more effective in modulating the innate immune response and antioxidant capacity of BMEC during in vitro iE-DAP stimulation.

Key words: amino acids, inflammation, innate immunity, NOD-like receptor 1

\section{INTRODUCTION}

Mastitis is a major issue in dairy herds impairing both economic benefit and health (Ruegg, 2017). When recognized by pattern recognition receptors (PRR), invading pathogens trigger the innate immune response in mammary gland (Kumar et al., 2011). Toll-like receptor 2 (TLR2) and Toll-like receptor 4 (TLR4) are transmembrane PRR and their crucial role in the infection of the udder has been demonstrated in dairy cows (Petzl et al., 2008). Nucleotide-binding oligomerization domain (NOD)-like receptors are cytosolic receptors and critical elements of innate immunity compensating for other pattern recognition systems (Franchi et al., 2009, Kim et al., 2016). By recognizing its specific ligand gamma-D-glutamyl-meso-diaminopimelic acid (iE-DAP) produced by all gram-negative and certain gram-positive bacteria, NOD-like receptor 1 (NOD1) plays a crucial role in the innate immunity of dairy cows (Porcherie et al., 2012; Tan et al., 2012). Previous studies showed that NOD-like receptors are associated with many inflammatory diseases (Fritz et al., 2006) including the innate immune response during mastitis (Porcherie et al., 2012).

Methionine (Met), an essential sulfur-containing AA, is a key nutrient for dairy cows and showed a positive effect on the inflammatory and antioxidant response 
in peripartal dairy cows (Osorio et al., 2014; Zhou et al., 2016; Batistel et al., 2018). Through the transsulfuration pathway, methyl donors can enhance synthesis of sulfur-containing antioxidants, such as taurine and glutathione (GSH; Lu, 2013). Glutathione peroxidases (GPx) activity relies on GSH availability and plays a fundamental role in cellular protection against reactive oxygen metabolites (ROM; Liang et al., 2020). In addition, the semi-essential AA arginine (Arg) is also important for immune capacity and has antiinflammatory properties (de Andrade Bernal Fagiani et al., 2019). Previous studies underscored the role of Arg as a functional AA with benefits on the modulation of inflammatory responses in primary bovine mammary epithelial cells (BMEC; Wu et al., 2016) and lactating dairy cows (Zhao et al., 2018) and also through an increase in GSH levels (Dasgupta et al., 2006).

Our group recently reported the effects of increased in vitro supply of Met and Arg on mRNA and protein abundance associated with innate immune response and redox balance during an in vitro LPS challenge in BMEC (Dai et al., 2020). Similar to LPS, iE-DAP is a pathogen-associated molecular pattern that plays a fundamental role in the mastitis pathogenesis and can induce an intense response when recognized by cytosolic NOD1 (Porcherie et al., 2012). Although our group has already reported in vivo studies investigating mastitis and nutrigenomics effects in the mammary gland (Loor et al., 2011; Han et al., 2018; Vailati-Riboni et al., 2018), there are no studies that have elucidated the effects of increased supply of both Met and Arg on innate immune and antioxidant responses induced through iE-DAP stimulation in BMEC.

The general hypothesis of the present study was that an increased supply of Met and Arg in the culture medium modulate molecular biomarkers of innate immunity in BMEC induced by exogenous challenge with iE-DAP. Thus, the specific objective was to measure the mRNA abundance of genes related to immune response, antioxidant function and AA metabolism.

\section{MATERIALS AND METHODS}

\section{Cell Culture and Treatments}

The BMEC $\left(2 \times 10^{5}\right.$ cells $)$ were seeded into 6 -well plates and incubated overnight with serum-free highglucose Dulbecco's modified Eagle's medium as described in our previous work (Dai et al., 2020). Subsequently, BMEC were pretreated for $12 \mathrm{~h}$ with modified medium: medium with ideal AA profile (control; Con), medium with increased Met supply (incMet), medium with increased Arg supply (incArg), or medium with increased Met plus Arg supply (incMetArg; Dai et al., 2020). After a 12-h incubation in modified medium, cells were treated with either $10 \mu \mathrm{g} / \mathrm{mL}$ of iE-DAP (iE, Sigma-Aldrich, St. Louis, MO) or PBS and incubated for another $6 \mathrm{~h}$. Thus, we generated a total of 8 treatments in a factorial arrangement: (1) Con, (2) incMet, (3) incArg, (4) incMetArg, (5) Con + iE-DAP, (6) incMet + iE-DAP, (7) incArg + iE-DAP, and (8) incMetArg + iE-DAP. All treatments were conducted with 4 replicates. Formulation of the medium used in the present study was described in our previous work (Dai et al., 2020).

\section{mRNA Extraction, cDNA Synthesis, and Quantitative Real-Time PCR}

Cells were collected at the end of the treatment and the miRNAeasy Kit (cat. no. 217004; Qiagen, Hilden, Germany) was used to extract mRNA from BMEC according to the manufacturer's instructions. The cDNA was synthesized, and quantitative real-time PCR (RT-qPCR) were performed using the same protocol as reported previously (Jacometo et al., 2015). Genes associated with immune response, oxidative stress, AA transporters, Arg metabolism, and Met metabolism were measured. Primers were designed and tested following a protocol reported previously by our group (Zhou et al., 2018). Ubiquitously expressed prefoldin like chaperone $(U X T), G A P D H$, and ribosomal protein S9 (RPS9) were selected as internal control genes (ICG). The geometric mean of the ICG was used to normalize the gene expression data, and the generated data were calculated following the method described by Zhou et al. (2018). All primer information and RT-qPCR performance data are available in a recent manuscript from our group (Dai et al., 2020).

\section{Statistical Analysis}

Statistical analysis was performed in a similar fashion as described previously (Dai et al., 2020) with some modifications. In brief, data were analyzed as a $2 \times$ $2 \times 2$ factorial arrangement of treatments using the MIXED procedure of SAS 9.4 (SAS Institute Inc., Cary, NC). Met, Arg, and iE-DAP were the 3 factors, each containing 2 levels: basal or increased levels of the AA and with or without iE-DAP, resulting in 8 treatments. The model included the main effects of Met, Arg, and iE-DAP, as well as all the following interactions: Met $\times$ Arg $\times$ iE-DAP, Met $\times$ iE-DAP, Arg $\times$ iE-DAP, and Met $\times$ Arg. The random effect was individual cell culture well. The Shapiro-Wilk test was applied to assess normality of distribution of variables. To fit nor- 
mal distribution of residuals, mRNA abundance data were $\log 2$-scale transformed before statistical analysis and then were $\log 2$ back-transformed as presented in tables and figures. Least squares means and standard errors were determined using the LSMEANS statement of SAS and were compared using Tukey's test when significant interactions were observed. Significance was set at $P \leq 0.05$ and tendencies at $P \leq 0.10$.

\section{RESULTS}

\section{Immune Response}

A 3-way interaction was observed for TLR 4 mRNA abundance $(P=0.006$; Figure 1$)$ due to lower TLR4 abundance in cultures with incMetArg $+\mathrm{iE-DAP}$ compared with cultures without iE-DAP stimulation $(P<$ 0.05; Figure 1). A 2-way interaction between Met and iE-DAP $(P=0.008)$ and between Arg and iE-DAP $(P$ $=0.008)$ was observed for NOD1 mRNA abundance (Table 1). This was due to greater NOD1 mRNA abundance in cultures with incMet $+\mathrm{iE}-\mathrm{DAP}$ compared with Con + iE-DAP $(P<0.001)$, and lower NOD1 mRNA abundance in cultures with incArg + iE-DAP compared with Con + iE-DAP $(P<0.001)$.

A 3-way interaction was observed for IL6 mRNA abundance $(P=0.04$; Figure 1$)$ due to greater IL6 abundance in cultures with incMetArg $+\mathrm{iE-DAP}$ compared with Con $+\mathrm{iE-DAP}(P<0.05)$ and with cultures without iE-DAP stimulation $(P<0.05)$ (Figure 1$)$.

The NFKB1 mRNA abundance tended to be lower overall in cultures with incMet supply $(P=0.06)$ and was lower overall in cultures with incArg supply $(P=$ 0.006; Table 1). Regardless of treatment, the iE-DAP stimulation upregulated NOS2 mRNA abundance $(P=$ 0.008; Table 1).

\section{Oxidative Stress}

A 3-way interaction was observed for GPX1 mRNA abundance $(P=0.04$; Figure 1$)$ due to greater $G P X 1$ abundance in cultures with incMetArg + iE-DAP compared with Con + iE-DAP $(P<0.05$; Figure 1$)$. A 2 -way interaction between Met and iE-DAP was observed for $S O D 1 \mathrm{mRNA}$ abundance $(P=0.02$; Table 1) due to greater $S O D 1$ abundance in cultures with incMet + iE-DAP compared with Con + iE-DAP $(P$ $=0.078$ ).

A 3-way interaction was observed for NFE2L2 mRNA abundance $(P=0.04$; Figure 1$)$ due to lower NFE2L2 abundance in cultures with incMetArg $+\mathrm{iE}$ DAP compared with Con + iE-DAP $(P<0.05)$ and with cultures without iE-DAP stimulation $(P<0.05$; Figure 1).
The $G S S(P=0.001)$ and $K E A P 1(P=0.04) \mathrm{mRNA}$ abundance was greater overall in cultures with incArg supply (Table 1). Regardless of treatment, the iE-DAP stimulation upregulated $G S R$ mRNA abundance $(P=$ 0.004; Table 1).

\section{Amino Acid Transporters}

A 3-way interaction was observed for SLC7A1 mRNA abundance $(P=0.002$; Figure 1$)$ due to greater $S L C 7 A 1$ abundance in cultures with incMet $+\mathrm{iE}-\mathrm{DAP}$ compared with Con + iE-DAP and with cultures without iE-DAP stimulation $(P<0.05)$. However, compared with Con - iE-DAP, cultures with incMetArg + iE-DAP had lower SLC7A1 abundance $(P<0.05)$, and cultures with incArg and incMetArg - iE-DAP had lower SLC7A1 abundance compared with both Con $\mathrm{iE-DAP}$ and Con $+\mathrm{iE-DAP}(P<0.05$; Figure 1$)$.

A 2-way interaction between Met and iE-DAP was observed for $S L C 3 A 2$ mRNA abundance $(P=0.05$; Table 1) due to greater SLC3A2 abundance in cultures with incMet + iE-DAP compared with Con + iE-DAP $(P<0.05)$. The incArg cultures had lower overall $S L$ C3A2 $(P<0.001)$, SLC7A5 $(P<0.001)$, and SLC38A9 $(P=0.003)$ mRNA abundance (Table 1$)$.

\section{Arginine and Methionine Metabolism-Related Genes}

There were no interactions or main effects on Met and Arg metabolism-related genes. Regardless of treatment, iE-DAP stimulation upregulated $S M S(P$ $=0.02), O D C 1(P=0.01)$, and $A M D 1(P<0.001)$ mRNA abundance (Table 1).

\section{DISCUSSION}

Bovine mammary epithelial cells contribute to the innate immune response during infection of the mammary gland by recognizing pathogens through PRR (IbeaghaAwemu et al., 2008; Huang et al., 2019). The NOD-like receptors are cytosolic PRR, which compensate for and synergize with other PRR, such as toll-like receptors (TLR) during infection (Cardenas et al., 2011). The protein NOD1 is one of the major NOD-like receptors and initiates the innate immune response by sensing the microbial component iE-DAP (Fritz et al., 2006). At least in nonruminants, after binding with iE-DAP, downstream signaling cascades including nuclear factor kappa B (NF- $\mathbf{k B})$ are activated and promote expression of genes related to the innate immune response (e.g., inflammatory cytokines; Franchi et al., 2009).

The lower TLR 4 abundance in cultures receiving increased Met and Arg and challenged with iE-DAP is opposite to previous studies in ruminants demonstrat- 

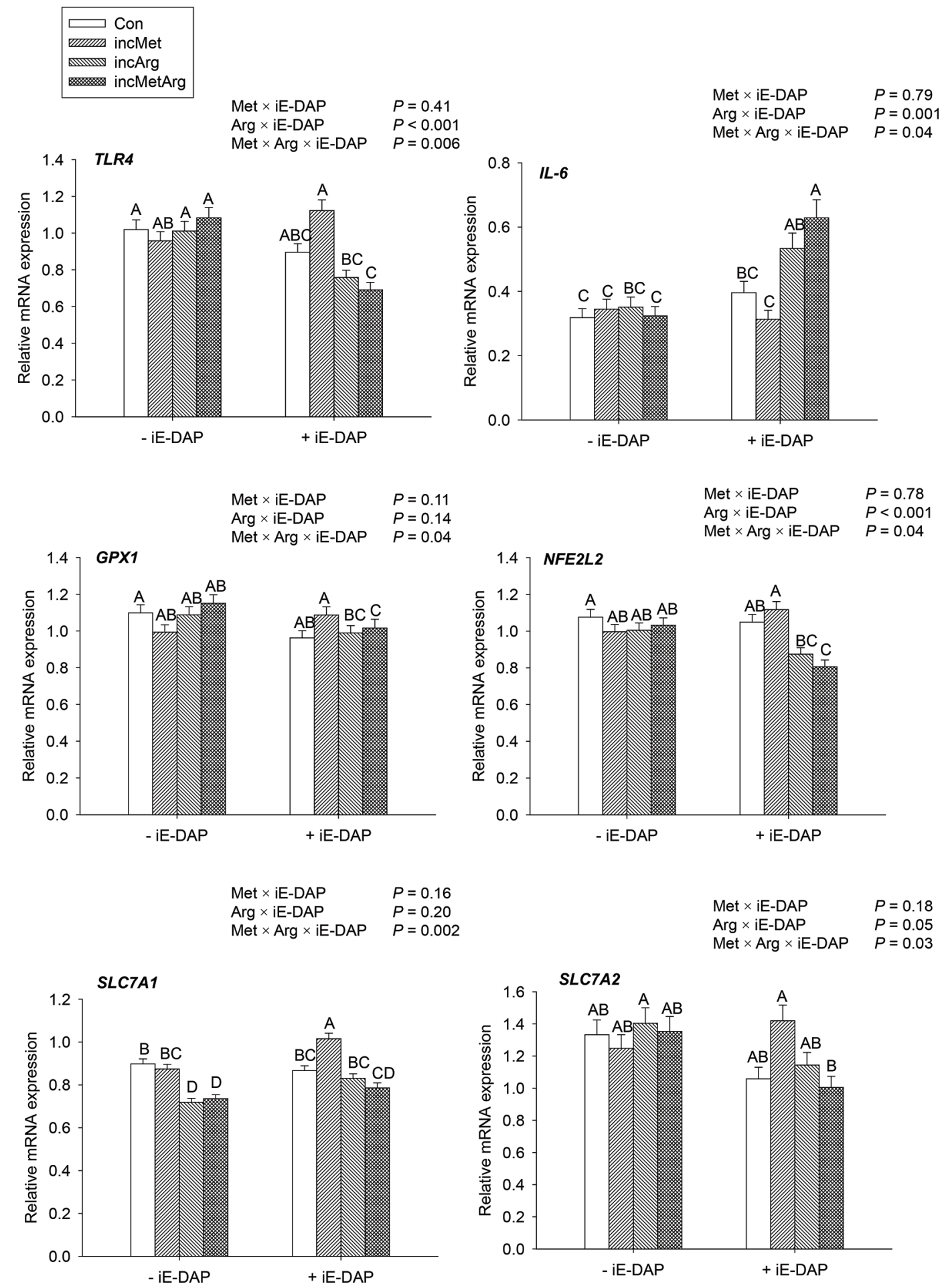

Figure 1. Abundance of mRNA for antioxidant genes in primary bovine mammary cells incubated with various AA treatments and challenged with or without $10 \mu \mathrm{g} / \mathrm{mL}$ gamma-D-glutamyl-meso-diaminopimelic acid (iE-DAP) for $6 \mathrm{~h}$. Treatments included the ideal AA profile at a ratio of Lys:Met 2.9:1 and Lys:Arg 2:1 (con) or different levels of Met and Arg to vary the Lys:Met and Lys:Arg as follows: Lys:Met 2.5:1 and Lys:Arg 2:1 (incMet), Lys:Met 2.9:1 and Lys:Arg 1:1 (incArg) and Lys:Met 2.5:1 and Lys:Arg 1:1 (incMetArg). Data reported here had a significant $(P<0.05)$ or tended $(P=0.10)$ to have a significant triple interaction $\left(\right.$ Met $\times \operatorname{Arg} \times$ iE-DAP). ${ }^{\text {A-D }}$ Means differ between treatments $(P<0.05)$. Main effects of Met, Arg, or iE-DAP along with 2-way interactions are reported in Table 1 . Error bars represent the SEM. TLR 4 $=$ toll-like receptor $4 ; I L 6=$ interleukin $6 ; G P X 1=$ glutathione peroxidase $1 ; N F E 2 L 2=$ nuclear factor, erythroid 2 like $2 ; S L C 7 A 1=$ solute carrier family 7 member $1 ; S L C 7 A 2=$ solute carrier family 7 member 2. 
Dai et al.: NOD1 ACTIVATION IN MAMMARY CELLS

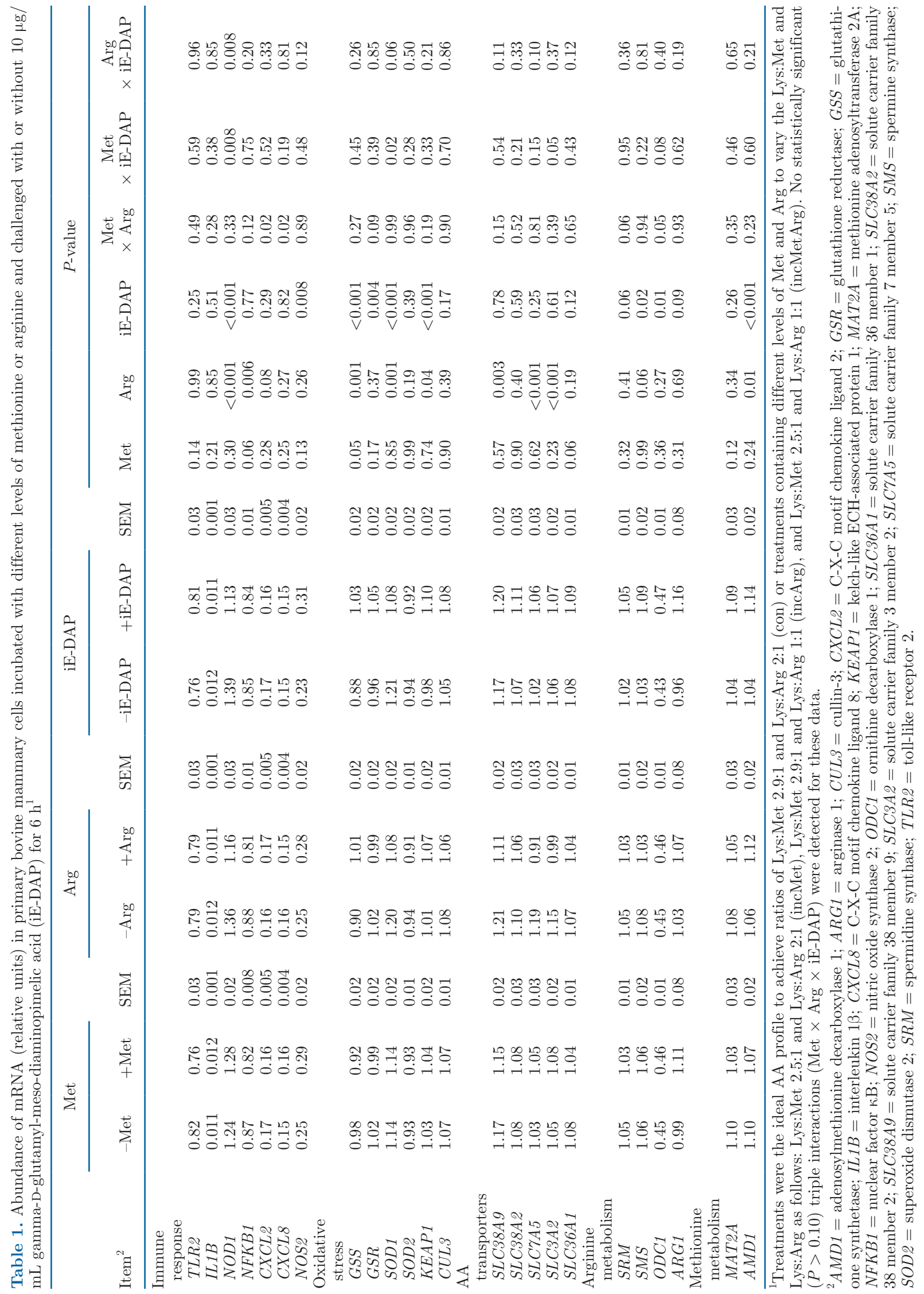


ing that mammary cells increase TLR 4 transcription after LPS stimulation (Bulgari et al., 2017; Wang et al., 2017). However, our recent work evaluating the increased Met and Arg supply in BMEC during the LPS challenge showed a similar response. A TLR4 downregulation was observed in BMEC after LPS challenge, coupled with a trend for lower TLR 4 abundance in incMet + LPS cultures (Dai et al., 2020). Thus, the assays with pathogen-associated molecular patterns (e.g., LPS and iE-DAP) in BMEC with increased Met and Arg led to a downregulation in TLR4 abundance, a response that might be associated with a protective effect of both AA to prevent an exacerbated inflammatory response.

In nonruminant cells, recognition of iE-DAP through the NOD1 receptor leads to activation of the NF- $\kappa \mathrm{B}$ pathway and stimulates transcription of inflammatory cytokines and others transcription factors (Chamaillard et al., 2003). Intriguingly, upregulation of NOD1 in cultures with incMet during the iE-DAP challenge did not stimulate greater NFKB1 abundance. Such response was opposite to the lower overall NFKB1 and NOD1 abundance during iE-DAP challenge in response to incArg suggesting this AA relieved the inflammatory response as reported in previous work with BMEC stimulated with LPS (Wu et al., 2016).

Interleukin 6 is a soluble mediator that contributes to host defense by modulating the immune response (Tanaka et al., 2014). A recent study demonstrated that iE-DAP stimulation of BMEC led to upregulation of both NOD1 and NFKB1 with a consequent increase in IL-6 abundance (Gao et al., 2020). In the present study, we speculate that greater IL- 6 abundance in incMetArg cultures without changes in NFKB1 might have been associated with stimulation of other transcription factors as already demonstrated in previous studies in nonruminants, such as nuclear factor IL-6, interferon regulatory factor 1 , and activator protein 1 (Akira and Kishimoto, 1992; Tanaka et al., 2014). Our previous work supplementing multiparous Holstein cows with rumen-protected Met detected greater IL-6 plasma concentrations in cows fed rumen-protected Met during the peripartal period (Zhou et al., 2016). We also demonstrated that blood polymorphonuclear cells exposed to LPS stimulation tended to have greater IL-6 abundance as exogenous Met supplementation increased (Vailati-Riboni et al., 2019). In the present study, the greater IL-6 abundance in incMetArg cultures after iEDAP stimulation suggested that increased availability of both AA played an important role in regulating the immune response. This cytokine has a dynamic functionality according to the interaction with specific receptors, acting as a proinflammatory inducer (trans signaling) or as an anti-inflammatory modulator (clas- sic signaling; Scheller et al., 2011). Understanding the meaning of the increased IL-6 abundance in cultures with Inc.MetArg after iE-DAP stimulation becomes challenging without evaluating protein abundance and receptor interactions. However, the absence of a significant difference in other proinflammatory-related genes (e.g., IL1B, NOS2) indicates that a possible IL-6 anti-inflammatory role might have contributed to modulating the immune response in cells challenged with iE-DAP and receiving exogenous Arg and Met in the culture medium.

Glutathione peroxidase 1 (GPX1) and superoxide dismutase 1 (SOD1) are key free-radical scavengers in the first line of antioxidant defense, and protect cells against ROM generated during cellular metabolism (Loor et al., 2013; Mohammedi et al., 2016; Ighodaro and Akinloye, 2018). The GSS gene encodes the enzyme glutathione synthetase (GSS), which plays a crucial role in the GSH synthesis through the gammaglutamyl cycle. Glutathione is the most potent cellular antioxidant used by GPX1 against cytosolic hydrogen peroxide (Aquilano et al., 2014). Nuclear factor, erythroid 2 like 2 (NFE2L2) is a transcription factor that once activated promotes the expression of genes with antioxidant response elements (e.g., GPX1, GSH, and SOD1) on their promoters (Pias et al., 2003; Ruiz et al., 2013).

The increased Met supply in BMEC was previously reported to be beneficial for the antioxidant response through increasing GPX1 and SOD1 enzymatic activity during hyperthermia-induced BMEC injury (Han et al., 2015). Our previous study with multiparous Holstein cows demonstrated that enhanced postruminal Met supply altered mammary gland antioxidant gene networks via phosphorylation of NFE2L2 (i.e., a response that led to greater GPX1 abundance in cows supplemented with Met during peripartal period; Han et al., 2018). In the present study, the greater GPX1 abundance with incMetArg after iE-DAP stimulation indicated that an increase in the supply of both AA can enhance the antioxidant capacity of BMEC during the iE-DAP challenge. In addition, the greater overall $G S S$ abundance with Arg supply underscored a more potent effect in the antioxidant response.

From a physiological point of view, the lower NFE2L2 abundance observed in cultures with incMetArg and incArg after iE-DAP stimulation is not in accordance with GPX1, GSS and SOD1 responses. The NFE2L2 downregulation might be partly explained by the overall upregulation of KEAP1 observed in cultures with incArg. The KEAP1 gene encodes the kelch-like ECHassociated protein 1 (KEAP1), which is often characterized as an inhibitor of NFE2L2 activity through its sequestration in the cytosol (Ho et al., 2005; Han et al., 
2018). The antagonistic response between NFE2L2 and $K E A P 1$ was demonstrated in our previous work with mammary tissue of cows fed rumen-protected Met; that is, NFE2L2 upregulation and KEAP1 downregulation with increased Met supply (Han et al., 2018). Thus, we speculate that increased Met and Arg might modulate transcription of antioxidant-related genes by affecting the interactions of NFE2L2/KEAP1. Further studies are required to elucidate the underlying mechanisms in detail.

Amino acid transporters play a crucial role in providing these molecules to help maintain cellular redox balance and key intracellular signaling mechanisms (Broer and Palacin, 2011). The SLC7A1 gene encodes a transporter for Arg and other cationic AA (Bronte and Zanovello, 2005). The former is often in short supply during stress conditions (Bansal and Ochoa, 2003). Thus, the greater $S L C 7 A 1$ abundance in response to incMet + iE-DAP suggested an increase in uptake of Arg to ensure a sufficient supply during the challenge. Recently our group demonstrated that increased Met supply in unstimulated BMEC upregulated SLC7A1 abundance, whereas greater Arg supply downregulated 5 of the 7 known mechanistic target of rapamycin complex 1-target AA transporters genes $(S L C 1 A 5, S L$ C3A2, SLCYA1, and SLCYA5; Hu et al., 2020). The lower $S L C^{\prime} 7 A 1 \mathrm{mRNA}$ abundance in response to greater Arg supply in unstimulated cells was also detected in previous studies with nonruminants and ruminants (Closs, 2002; Hatzoglou et al., 2004; Dai et al., 2020). According to (Hu et al., 2020), the opposite response in SLC7A1 abundance due to greater Met or Arg supply suggested that BMEC has a different sensitivity to the additional Met or Arg supply. The marked downregulation in several AA transporters (SLC7A1, SLC7A5, SLC3A2, and SLC38A9) in cultures with incArg suggested that a negative feedback mechanism helps regulate AA uptake in situations where the AA levels are already adequate (Hu et al., 2020).

The SLC3A2 gene is a member of the solute carrier family 3 member 2 , which encodes a bidirectional antiporter that regulates the exchange of L-AA between the extracellular and intracellular compartments (Nicklin et al., 2009). Our recent work underscored that enhanced postruminal supply of Met led to greater $S L$ C3A2 mRNA abundance in adipose tissue of Holstein cows during the periparturient period (Liang et al., 2019). As in the present study, upregulation of SLC3A2 in cultures with incMet was also observed in MAC-T cells (Dong et al., 2018) and human muscle tissue with increased essential AA supplementation (Drummond et al., 2010). Mechanistically, the upregulation of SLC3A2 with greater Met supply supports the role of AA for maintenance of an efficient immune response as pre- viously demonstrated in rodents (Ikeda et al., 2017). Overall, the greater $S L C 7 A 1$ abundance with incMet in both iE-DAP stimulated and nonstimulated cultures compared with controls suggested a beneficial effect of Met on AA utilization in BMEC, a response supported by the upregulation of SLC3A2 with incMet supply during the iE-DAP challenge.

Polyamines (e.g., putrescine, spermidine, and spermine) are bioactive amines that act on cell regulation, DNA transcription and RNA translation, protein synthesis, and modulation of the immune response (Larqué et al., 2007). Among polyamines, spermine is considered the most active in the control of various biological processes (Yuan et al., 2001). The SMS gene encodes spermine synthase, which catalyzes the production of spermine from spermidine (Kalač, 2014). The ODC1 gene encodes ornithine decarboxylase 1 (ODC1), a rate-limiting enzyme in the polyamine biosynthesis pathway, which catalyzes the production of putrescine from ornithine (Schipper and Verhofstad, 2002). The AMD1 gene encodes adenosylmethionine decarboxylase 1 (AMD1), an intermediate enzyme in polyamine biosynthesis (Larqué et al., 2007). The upregulation in mRNA abundance of the various components of the polyamine pathway after iE-DAP stimulation, regardless of treatment, might have been related to a cellular protection mechanism in an attempt to counteract the inflammatory response.

Spermine is considered the most effective polyamine in regulating ODC1 activity and its concentrations are often increased during infectious and inflammatory processes (Zhang et al., 1997; Yuan et al., 2001). An increase in spermine in human mononuclear cells during LPS challenge inhibited proinflammatory cytokine synthesis (Zhang et al., 1997). Upregulation of NOS2, which encodes an inducible nitric oxide synthase (NOS), during iE-DAP stimulation suggested an increase in nitric oxide (NO) production, an essential component of the oxidative burst during the phagocytic response (Bogdan, 2015). Previous studies in rodents reported that spermine downregulated NOS mRNA abundance and NO concentrations in macrophages challenged with LPS (Southan et al., 1994; Mossner et al., 2001). Although we did not determine concentrations of polyamines, we speculate that upregulation of the polyamine pathway to increase spermine levels was necessary. It represented a counter-regulatory mechanism to dampen production of $\mathrm{NO}$ and an exacerbated proinflammatory response during iE-DAP challenge.

\section{CONCLUSIONS}

Enhanced supply of Met and Arg in the culture medium was beneficial for modulation of the innate 
immune response and antioxidant capacity in BMEC during inflammatory stimulation with the peptidoglycan iE-DAP. Such effects encompass proinflammatory and antioxidant responses coupled with AA transport mechanisms. The functional relevance of these responses in vivo remains to be determined.

\section{ACKNOWLEDGMENTS}

H. Dai and L. Hu received scholarships from China Scholarship Council (Beijing, China) to undertake PhD and MS training at the University of Illinois, Urbana. M. Gomes Lopes was supported in part by a fellowship from Coordenação de Aperfeiçoamento de Pessoal de Nível Superior-Brazil (CAPES, finance Code 001) and by Hatch funds under project ILLU-538-914, National Institute of Food and Agriculture (Washington, DC). The authors claim no conflicts of interest.

\section{REFERENCES}

Akira, S., and T. Kishimoto. 1992. IL-6 and NF-IL6 in acute-phase response and viral infection. Immunol. Rev. 127:25-50. https://doi .org/10.1111/j.1600-065X.1992.tb01407.x.

Aquilano, K., S. Baldelli, and M. R. Ciriolo. 2014. Glutathione: New roles in redox signaling for an old antioxidant. Front. Pharmacol. 5:196. https://doi.org/10.3389/fphar.2014.00196.

Bansal, V., and J. B. Ochoa. 2003. Arginine availability, arginase, and the immune response. Curr. Opin. Clin. Nutr. Metab. Care 6:223-228. https://doi.org/10.1097/00075197-200303000-00012.

Batistel, F., J. M. Arroyo, C. I. M. Garces, E. Trevisi, C. Parys, M. A. Ballou, F. C. Cardoso, and J. J. Loor. 2018. Ethyl-cellulose rumen-protected methionine alleviates inflammation and oxidative stress and improves neutrophil function during the periparturient period and early lactation in Holstein dairy cows. J. Dairy Sci. 101:480-490. https://doi.org/10.3168/jds.2017-13185.

Bogdan, C. 2015. Nitric oxide synthase in innate and adaptive immunity: An update. Trends Immunol. 36:161-178. https://doi.org/10 $.1016 /$ j.it.2015.01.003.

Bröer, S., and M. Palacín. 2011. The role of amino acid transporters in inherited and acquired diseases. Biochem. J. 436:193-211. https:/ /doi.org/10.1042/BJ20101912.

Bronte, V., and P. Zanovello. 2005. Regulation of immune responses by L-arginine metabolism. Nat. Rev. Immunol. 5:641-654. https:/ /doi.org/10.1038/nri1668.

Bulgari, O., X. Dong, A. L. Roca, A. M. Caroli, and J. J. Loor. 2017. Innate immune responses induced by lipopolysaccharide and lipoteichoic acid in primary goat mammary epithelial cells. J. Anim. Sci. Biotechnol. 8:29. https://doi.org/10.1186/s40104-017-0162-8.

Cardenas, I., M. J. Mulla, K. Myrtolli, A. K. Sfakianaki, E. R. Norwitz, S. Tadesse, S. Guller, and V. M. Abrahams. 2011. Nod1 activation by bacterial iE-DAP induces maternal-fetal inflammation and preterm labor. J. Immunol. 187:980-986. https://doi.org/10 $.4049 /$ jimmunol.1100578.

Chamaillard, M., M. Hashimoto, Y. Horie, J. Masumoto, S. Qiu, L. Saab, Y. Ogura, A. Kawasaki, K. Fukase, S. Kusumoto, M. A. Valvano, S. J. Foster, T. W. Mak, G. Nuñez, and N. Inohara. 2003. An essential role for NOD1 in host recognition of bacterial peptidoglycan containing diaminopimelic acid. Nat. Immunol. 4:702-707. https://doi.org/10.1038/ni945.

Closs, E. I. 2002. Expression, regulation and function of carrier proteins for cationic amino acids. Curr. Opin. Nephrol. Hypertens. 11:99-107. https://doi.org/10.1097/00041552-200201000-00015.
Dai, H., D. N. Coleman, L. Hu, I. Martinez-Cortes, M. Wang, C. Parys, X. Shen, and J. J. Loor. 2020. Methionine and arginine supplementation alter inflammatory and oxidative stress responses during lipopolysaccharide challenge in bovine mammary epithelial cells in vitro. J. Dairy Sci. 103:676-689. https://doi.org/10.3168/ jds.2019-16631.

Dasgupta, T., R. P. Hebbel, and D. K. Kaul. 2006. Protective effect of arginine on oxidative stress in transgenic sickle mouse models Free Radic. Biol. Med. 41:1771-1780. https://doi.org/10.1016/j .freeradbiomed.2006.08.025.

de Andrade Bernal Fagiani, M., A. Fluminhan, F. de Azevedo Mello, D. Yabuki, G. V. Gonçalves, L. K. Tsujigushi, L. G. Pereira, K. A. da Silva, S. B. B. da Silva, C. L. Santarem, P. F. I. Giozo, and L. S. L. de Souza Reis. 2019. L-arginine minimizes immunosuppression and prothrombin time and enhances the genotoxicity of 5-fluorouracil in rats. Nutrition 66:94-100. https://doi.org/10.1016/j.nut .2019.04.012.

Dong, X., Z. Zhou, B. Saremi, A. Helmbrecht, Z. Wang, and J. J. Loor. 2018. Varying the ratio of Lys:Met while maintaining the ratios of Thr:Phe, Lys:Thr, Lys:His, and Lys:Val alters mammary cellular metabolites, mammalian target of rapamycin signaling, and gene transcription. J. Dairy Sci. 101:1708-1718. https://doi.org/ 10.3168/jds.2017-13351.

Drummond, M. J., E. L. Glynn, C. S. Fry, K. L. Timmerman, E. Volpi, and B. B. Rasmussen. 2010. An increase in essential amino acid availability upregulates amino acid transporter expression in human skeletal muscle. Am. J. Physiol-Endoc M. 298:E1011-E1018.

Franchi, L., N. Warner, K. Viani, and G. Nuñez. 2009. Function of Nod-like receptors in microbial recognition and host defense. Immunol. Rev. 227:106-128. https://doi.org/10.1111/j.1600-065X .2008.00734.x.

Fritz, J. H., R. L. Ferrero, D. J. Philpott, and S. E. Girardin. 2006. Nod-like proteins in immunity, inflammation and disease. Nat. Immunol. 7:1250-1257. https://doi.org/10.1038/ni1412.

Gao, Q., Y. Wang, N. Ma, H. Dai, A. C. Roy, G. Chang, X. Shi, and X. Shen. 2020. Sodium valproate attenuates the iE-DAP induced inflammatory response by inhibiting the NOD1-NF-kB pathway and histone modifications in bovine mammary epithelial cells. Int. Immunopharmacol. 83:106392. https://doi.org/10.1016/j.intimp .2020 .106392 .

Han, L., F. Batistel, Y. Ma, A. S. M. Alharthi, C. Parys, and J. J. Loor. 2018. Methionine supply alters mammary gland antioxidant gene networks via phosphorylation of nuclear factor erythroid 2-like 2 (NFE2L2) protein in dairy cows during the periparturient period. J. Dairy Sci. 101:8505-8512. https://doi.org/10.3168/jds .2017-14206.

Han, Z.-Y., T. Mu, and Z. Yang. 2015. Methionine protects against hyperthermia-induced cell injury in cultured bovine mammary epithelial cells. Cell Stress Chaperones 20:109-120. https://doi.org/ 10.1007/s12192-014-0530-7.

Hatzoglou, M., J. Fernandez, I. Yaman, and E. Closs. 2004. Regulation of cationic amino acid transport: The story of the CAT-1 transporter. Annu. Rev. Nutr. 24:377-399. https://doi.org/10.1146/ annurev.nutr.23.011702.073120.

Ho, H. K., C. C. White, C. Fernandez, N. Fausto, T. J. Kavanagh, S. D. Nelson, and S. A. Bruschi. 2005. Nrf2 activation involves an oxidative-stress independent pathway in tetrafluoroethylcysteineinduced cytotoxicity. Toxicol. Sci. 86:354-364. https://doi.org/10 .1093/toxsci/kfi205.

Hu, L., Y. Chen, I. M. Cortes, D. N. Coleman, H. Dai, Y. Liang, C. Parys, C. Fernandez, M. Wang, and J. J. Loor. 2020. Supply of methionine and arginine alters phosphorylation of mechanistic target of rapamycin (mTOR), circadian clock proteins, and alpha-s1casein abundance in bovine mammary epithelial cells. Food Funct. 11:883-894. https://doi.org/10.1039/C9FO02379H.

Huang, Y., L. Shen, J. Jiang, Q. Xu, Z. Luo, Q. Luo, S. Yu, X. Yao, Z. Ren, Y. Hu, Y. Yang, and S. Cao. 2019. Metabolomic profiles of bovine mammary epithelial cells stimulated by lipopolysaccharide. Sci. Rep. 9:19131. https://doi.org/10.1038/s41598-019-55556-2.

Ibeagha-Awemu, E. M., J. W. Lee, A. E. Ibeagha, D. D. Bannerman, M. J. Paape, and X. Zhao. 2008. Bacterial lipopolysaccharide in- 
duces increased expression of toll-like receptor (TLR) 4 and downstream TLR signaling molecules in bovine mammary epithelial cells. Vet. Res. 39:11. https://doi.org/10.1051/vetres:2007047.

Ighodaro, O. M., and O. A. Akinloye. 2018. First line defence antioxidants-superoxide dismutase (SOD), catalase (CAT) and glutathione peroxidase (GPX): Their fundamental role in the entire antioxidant defence grid. Alexandria J. Med. 54:287-293. https:// doi.org/10.1016/j.ajme.2017.09.001.

Ikeda, K., M. Kinoshita, H. Kayama, S. Nagamori, P. Kongpracha, E. Umemoto, R. Okumura, T. Kurakawa, M. Murakami, N. Mikami, Y. Shintani, S. Ueno, A. Andou, M. Ito, H. Tsumura, K. Yasutomo, K. Ozono, S. Takashima, S. Sakaguchi, Y. Kanai, and K. Takeda. 2017. Slc3a2 mediates branched-chain amino-acid-dependent maintenance of regulatory T cells. Cell Rep. 21:1824-1838. https://doi.org/10.1016/j.celrep.2017.10.082.

Jacometo, C. B., J. S. Osorio, M. Socha, M. N. Correa, F. PiccioliCappelli, E. Trevisi, and J. J. Loor. 2015. Maternal consumption of organic trace minerals alters calf systemic and neutrophil mRNA and microRNA indicators of inflammation and oxidative stress. J. Dairy Sci. 98:7717-7729. https://doi.org/10.3168/jds.2015-9359.

Kalač, P. 2014. Health effects and occurrence of dietary polyamines: A review for the period 2005-mid 2013. Food Chem. 161:27-39. https://doi.org/10.1016/j.foodchem.2014.03.102.

Kim, Y. K., J. S. Shin, and M. H. Nahm. 2016. NOD-like receptors in infection, immunity, and diseases. Yonsei Med. J. 57:5-14. https:/ /doi.org/10.3349/ymj.2016.57.1.5.

Kumar, H., T. Kawai, and S. Akira. 2011. Pathogen recognition by the innate immune system. Int. Rev. Immunol. 30:16-34. https://doi .org/10.3109/08830185.2010.529976.

Larqué, E., M. Sabater-Molina, and S. Zamora. 2007. Biological significance of dietary polyamines. Nutrition 23:87-95. https://doi .org/10.1016/j.nut.2006.09.006.

Liang, Y., A. S. Abdulrahman, R. Bucktrout, A. A. Elolimy, V. Lopreiato, I. Martinez-Cortés, C. Xu, C. Fernandez, E. Trevisi, and J. J. Loor. 2020. Body condition alters glutathione and nuclear factor erythroid 2-like 2 (NFE2L2)-related antioxidant network abundance in subcutaneous adipose tissue of periparturient Holstein cows. J. Dairy Sci. 103:6439-6453. https://doi.org/10.3168/ jds.2019-17813.

Liang, Y., F. Batistel, C. Parys, and J. J. Loor. 2019. Methionine supply during the periparturient period enhances insulin signaling, amino acid transporters, and mechanistic target of rapamycin pathway proteins in adipose tissue of Holstein cows. J. Dairy Sci. 102:4403-4414. https://doi.org/10.3168/jds.2018-15738.

Loor, J. J., M. Bionaz, and J. K. Drackley. 2013. Systems physiology in dairy cattle: Nutritional genomics and beyond. Annu. Rev. Anim. Biosci. 1:365-392. https://doi.org/10.1146/annurev-animal -031412-103728.

Loor, J. J., K. M. Moyes, and M. Bionaz. 2011. Functional adaptations of the transcriptome to mastitis-causing pathogens: The mammary gland and beyond. J. Mammary Gland Biol. Neoplasia 16:305-322. https://doi.org/10.1007/s10911-011-9232-2.

Lu, S. C. 2013. Glutathione synthesis. Biochim. Biophys. Acta 1830:3143-3153. https://doi.org/10.1016/j.bbagen.2012.09.008.

Mohammedi, K., T. A. Patente, N. Bellili-Muñoz, F. Driss, H. Le Nagard, F. Fumeron, R. Roussel, S. Hadjadj, M. L. Corrêa-Giannella, M. Marre, and G. Velho. 2016. Glutathione peroxidase-1 gene (GPX1) variants, oxidative stress and risk of kidney complications in people with type 1 diabetes. Metabolism 65:12-19. https://doi .org/10.1016/j.metabol.2015.10.004.

Mössner, J., R. Hammermann, and K. Racké. 2001. Concomitant down-regulation of L-arginine transport and nitric oxide (NO) synthesis in rat alveolar macrophages by the polyamine spermine. Pulm. Pharmacol. Ther. 14:297-305. https://doi.org/10.1006/ pupt.2001.0297.

Nicklin, P., P. Bergman, B. Zhang, E. Triantafellow, H. Wang, B. Nyfeler, H. Yang, M. Hild, C. Kung, C. Wilson, V. E. Myer, J. P. MacKeigan, J. A. Porter, Y. K. Wang, L. C. Cantley, P. M. Finan, and L. O. Murphy. 2009. Bidirectional transport of amino acids regulates mTOR and autophagy. Cell 136:521-534. https:// doi.org/10.1016/j.cell.2008.11.044.
Osorio, J. S., E. Trevisi, P. Ji, J. K. Drackley, D. Luchini, G. Bertoni, and J. J. Loor. 2014. Biomarkers of inflammation, metabolism, and oxidative stress in blood, liver, and milk reveal a better immunometabolic status in peripartal cows supplemented with Smartamine M or MetaSmart. J. Dairy Sci. 97:7437-7450. https://doi .org/10.3168/jds.2013-7679.

Petzl, W., H. Zerbe, J. Günther, W. Yang, H. M. Seyfert, G. Nürnberg, and H. J. Schuberth. 2008. Escherichia coli, but not Staphylococcus aureus triggers an early increased expression of factors contributing to the innate immune defense in the udder of the cow. Vet. Res. 39:18. https://doi.org/10.1051/vetres:2007057.

Pias, E. K., O. Y. Ekshyyan, C. A. Rhoads, J. Fuseler, L. Harrison, and T. Y. Aw. 2003. Differential effects of superoxide dismutase isoform expression on hydroperoxide-induced apoptosis in PC-12 cells. J. Biol. Chem. 278:13294-13301. https://doi.org/10.1074/jbc .M208670200.

Porcherie, A., P. Cunha, A. Trotereau, P. Roussel, F. B. Gilbert, P. Rainard, and P. Germon. 2012. Repertoire of Escherichia coli agonists sensed by innate immunity receptors of the bovine udder and mammary epithelial cells. Vet. Res. 43:14. https://doi.org/10 .1186/1297-9716-43-14.

Ruegg, P. L. 2017. A 100-year review: Mastitis detection, management, and prevention. J. Dairy Sci. 100:10381-10397. https://doi .org/10.3168/jds.2017-13023.

Ruiz, S., P. E. Pergola, R. A. Zager, and N. D. Vaziri. 2013. Targeting the transcription factor Nrf2 to ameliorate oxidative stress and inflammation in chronic kidney disease. Kidney Int. 83:1029-1041. https://doi.org/10.1038/ki.2012.439.

Scheller, J., A. Chalaris, D. Schmidt-Arras, and S. Rose-John. 2011. The pro- and anti-inflammatory properties of the cytokine interleukin-6. Biochim. Biophys. Acta 1813:878-888. https://doi.org/ 10.1016/j.bbamcr.2011.01.034.

Schipper, R. G., and A. A. Verhofstad. 2002. Distribution patterns of ornithine decarboxylase in cells and tissues: Facts, problems, and postulates. J. Histochem. Cytochem. 50:1143-1160. https:// doi.org/10.1177/002215540205000901.

Southan, G. J., C. Szabó, and C. Thiemermann. 1994. Inhibition of the induction of nitric oxide synthase by spermine is modulated by aldehyde dehydrogenase. Biochem. Biophys. Res. Commun. 203:1638-1644. https://doi.org/10.1006/bbrc.1994.2374.

Tan, X., W. W. Li, J. Guo, and J. Y. Zhou. 2012. Down-regulation of NOD1 in neutrophils of periparturient dairy cows. Vet. Immunol. Immunopathol. 150:133-139. https://doi.org/10.1016/j.vetimm .2012.09.004.

Tanaka, T., M. Narazaki, and T. Kishimoto. 2014. IL-6 in inflammation, immunity, and disease. Cold Spring Harb. Perspect. Biol. 6:a016295.

Vailati-Riboni, M., R. E. Bucktrout, S. Zhan, A. Geiger, J. C. McCann, R. M. Akers, and J. J. Loor. 2018. Higher plane of nutrition pre-weaning enhances Holstein calf mammary gland development through alterations in the parenchyma and fat pad transcriptome. BMC Genomics 19:900. https://doi.org/10.1186/s12864-018-5303 -8 .

Vailati-Riboni, M., T. Xu, B. Qadir, R. Bucktrout, C. Parys, and J. J. Loor. 2019. In vitro methionine supplementation during lipopolysaccharide stimulation modulates immunometabolic gene network expression in isolated polymorphonuclear cells from lactating Holstein cows. J. Dairy Sci. 102:8343-8351. https://doi.org/10.3168/ jds.2018-15737.

Wang, Y., X. Zhang, Z. Wei, J. Wang, Y. Zhang, M. Shi, Z. Yang, and Y. Fu. 2017. Platycodin D suppressed LPS-induced inflammatory response by activating LXR $\alpha$ in LPS-stimulated primary bovine mammary epithelial cells. Eur. J. Pharmacol. 814:138-143. https: //doi.org/10.1016/j.ejphar.2017.07.037.

Wu, T., C. Wang, L. Ding, Y. Shen, H. Cui, M. Wang, and H. Wang. 2016. Arginine relieves the inflammatory response and enhances the casein expression in bovine mammary epithelial cells induced by lipopolysaccharide. Mediators Inflamm. 2016:9618795. https:// doi.org/10.1155/2016/9618795.

Yuan, Q., R. M. Ray, M. J. Viar, and L. R. Johnson. 2001. Polyamine regulation of ornithine decarboxylase and its antizyme in intesti- 
nal epithelial cells. Am. J. Physiol. Gastrointest. Liver Physiol. 280:G130-G138. https://doi.org/10.1152/ajpgi.2001.280.1.G130.

Zhang, M., T. Caragine, H. Wang, P. S. Cohen, G. Botchkina, K. Soda, M. Bianchi, P. Ulrich, A. Cerami, B. Sherry, and K. J. Tracey. 1997. Spermine inhibits proinflammatory cytokine synthesis in human mononuclear cells: A counterregulatory mechanism that restrains the immune response. J. Exp. Med. 185:1759-1768. https: //doi.org/10.1084/jem.185.10.1759.

Zhao, F. F., T. Y. Wu, H. R. Wang, L. Y. Ding, G. Ahmed, H. W. Li, W. Tian, and Y. Z. Shen. 2018. Jugular arginine infusion relieves lipopolysaccharide-triggered inflammatory stress and improves immunity status of lactating dairy cows. J. Dairy Sci. 101:5961-5970. https://doi.org/10.3168/jds.2017-13850.

Zhou, Z., O. Bulgari, M. Vailati-Riboni, E. Trevisi, M. A. Ballou, F C. Cardoso, D. N. Luchini, and J. J. Loor. 2016. Rumen-protected methionine compared with rumen-protected choline improves immunometabolic status in dairy cows during the peripartal peri- od. J. Dairy Sci. 99:8956-8969. https://doi.org/10.3168/jds.2016 $-10986$

Zhou, Z., F. Ferdous, P. Montagner, D. N. Luchini, M. N. Corrêa, and J. J. Loor. 2018. Methionine and choline supply during the peripartal period alter polymorphonuclear leukocyte immune response and immunometabolic gene expression in Holstein cows. J. Dairy Sci. 101:10374-10382. https://doi.org/10.3168/jds.2018-14972.

\section{ORCIDS}

D. N. Coleman @ https://orcid.org/0000-0002-8783-095X

M. G. Lopes @ https://orcid.org/0000-0003-3955-445X

I. Martinez-Cortés ๑ https://orcid.org/0000-0001-6851-5308

X. Shen ๑ https://orcid.org/0000-0002-3020-5010

J. J. Loor (® https://orcid.org/0000-0003-1586-4365 